\title{
EDUCAÇÃO AMBIENTAL E GERAÇÃO DE RESÍDUOS: A VISITAÇÃO NA PRAIA BRAVA DE BOIÇUCANGA - PARQUE ESTADUAL DA SERRA DO MAR, NÚCLEO DE SÃO SEBASTIÃO/SP
}

\section{Larissa Garcia de Almeida ${ }^{1}$ \\ Fernando Protti Bueno ${ }^{2}$}

\section{RESUMO}

A categoria parques de unidades de conservação, ao mesmo tempo que busca preservar a natureza, permite seu uso indireto. Destes, a visitação turístico-recreativa, mesmo que apenas contemplativa, ocasiona impactos. Nesse sentido, a educação e interpretação ambiental buscam formas de minimizar tais impactos, dentre estes a geração de resíduos. Diante disso, a presente pesquisa teve por objetivo identificar as ações de educação ambiental desenvolvidas no Parque Estadual da Serra do Mar - Núcleo de São Sebastião, de modo a buscar minimizar os impactos gerados pela visitação na Praia Brava de Boiçucanga, especificamente aqueles vinculados a geração de resíduos. A metodologia contou com estudo bibliográfico e documental para maior entendimento do objeto de estudo e na elaboração dos instrumentos. Foram realizadas observações in loco por meio de roteiros do espaço, estrutura e elementos presentes na trilha de acesso à Praia Brava (placas informativas e interpretativas) e do comportamento do visitante na trilha e na praia e, posteriormente, se realizou entrevista estruturada junto ao gestor do Parque. Notou-se que há poucas placas interpretativas e informativas na trilha e estas não atuam de modo eficiente, sendo que há ausência de lixeiras, o que supostamente pode interferir no comportamento do visitante. Entende-se que a maior parte do lixo presente na praia é proveniente do mar, no entanto, há visitantes que deixam o lixo na areia ou próximo à mata. Por fim, o Parque utiliza as placas e a entrega de folhetos como forma de educação e interpretação ambiental para minimizar os impactos causados, especificamente a geração de resíduos.

Palavras - chave: Áreas protegidas; educação ambiental; geração de resíduos.

\section{ABSTRACT}

The category parks of conservation units while seeking to preserve nature, allows its indirect use. Of these, the tourist-recreational visitation, even if only contemplative, causes impacts. In this sense, environmental education and interpretation seek ways to minimize such impacts, among which is the generation of waste. In view of this, this research aimed to identify the actions of environmental education developed in the State Park of Serra do Mar - São Sebastião Nucleus, in order to seek to minimize the impacts generated by the visitation in Praia Brava de Boiçucanga, specifically those linked to the generation of Waste. The methodology had a bibliographic and documentary study for a better understanding of the object of study and the elaboration of the instruments. On site observations were made through screenings of the space, structure and elements present on the access trail to Brava Beach (informative and interpretative plates) and visitor behavior on the trail and on the beach, and, later, a structured interview was conducted with the Manager of the Park. It was

\footnotetext{
${ }^{1}$ Graduada em Turismo. Universidade Estadual Paulista (UNESP), câmpus de Rosana.

E-mail: 1ari-.-@live.com

${ }^{2}$ Professor do Curso de Turismo. Universidade Estadual Paulista (UNESP), câmpus de Rosana.

E-mail: fbueno@rosana.unesp.br
} 
noted that there are few interpretive and informative signs on the trail and these do not work efficiently, and there are no dumps, which may interfere with visitor behavior. It is understood that most of the litter present on the beach comes from the sea, however, there are visitors who leave the garbage in the sand or near the woods. Finally, the Park uses the plates and the delivery of leaflets as a form of education and environmental interpretation to minimize the impacts caused, specifically the generation of waste.

Keywords: Protected areas; environmental education; waste generation.

\section{INTRODUÇÃO}

Com a possibilidade de ser trabalhada nos mais variados contextos e em espaços que permitem o contato direto com a natureza, por meio do estudo do meio, das trilhas interpretativas e do ecoturismo, a educação ambiental deve ser baseada em um modelo de desenvolvimento voltado para a conservação e a utilização racional dos recursos naturais, de forma a garantir a qualidade de vida das futuras gerações (GUIMARÃES, 2013; PHILIPPI JR., MAGLIO, 2005; NEIMAN, 2008).

Dentre os espaços que possibilitam o desenvolvimento da educação ambiental, estão as unidades de conservação (UCs). No Brasil, a responsabilidade pela implantação e gestão destas áreas protegidas são dos órgãos competentes distribuídos nas diferentes esferas de atuação (federal, estadual e municipal, além da iniciativa privada e das entidades do terceiro setor). A base legal para a criação e implantação das UCs no Brasil é o Sistema Nacional de Unidades de Conservação (SNUC), que tem por objetivo organizar e regulamentar as UCs, inclusive as categorias pertencentes ao grupo de proteção integral, no caso, os parques, que possuem o objetivo de "[...] preservar a natureza, sendo admitido apenas o uso indireto dos seus recursos naturais” (BRASIL, 2000, s.p).

Nesse contexto, a atividade de visitação em UCs para fins turístico-recreativos pode ser considerada um importante instrumento de percepção, educação e interpretação ambiental, pois pode sensibilizar e conscientizar os visitantes. Assim, o processo de visitação, de modo planejado e organizado, procura possibilitar que o visitante maximize o contato com a natureza ao mesmo tempo em que minimiza os impactos negativos gerados pela sua presença no local, algo que, por muitas vezes, ocorre devido à falta de informações e de manutenção dessas áreas (BARROS, 1997; HENRIQUES, 2008).

Com a intenção de assegurar a integral proteção da fauna, flora e da paisagem, as UCs presentes no Estado de São Paulo são de fundamental importância na proteção de sua biodiversidade. Em seu litoral, estão presentes a representação dos principais ecossistemas costeiros do Brasil, especificamente na Serra do Mar, que forma o maior corredor de biodiversidade de toda a Mata Atlântica (SMA, 2006).

O Parque Estadual da Serra do Mar está organizado em oito núcleos administrativos, agrupados de acordo com o uso do solo e de seus programas de manejo, que requerem diferentes formas de administração, levando em conta o domínio de terras e as condições de regularização fundiária. Contudo, a visitação pode ser impactante ao propósito da conservação 
ambiental no entorno das UCs, sendo necessária a identificação dos impactos, a setorização e a construção de recomendações para que se possa minimizá-los ou desenvolver métodos amigáveis à conservação (SMA, 2006).

Diante disso, a educação do visitante e o planejamento da visitação tornam-se essenciais para a busca de redução dos possíveis problemas que a sociedade vem ocasionando ao ambiente natural, assim como a busca de mudanças de atitude e a necessidade de intervenção para que os efeitos desses impactos sejam minimizados. Nesse caso, as UCs surgem como estratégia para a conservação da biodiversidade e vem sendo cada vez mais procuradas por pessoas que desejam maior contato com a natureza e também desfrutar dos benefícios que esse contato pode proporcionar (GIRALDELLA, NEIMAN, 2010).

Diante disso, a pesquisa no PESM foi escolhida porque toda UC que tenha visitação de forma desordenada, tende a sofrer com a geração de resíduos. Isto posto, a educação ambiental pode ser considerada uma forma de mitigar e mudar esse problema, ou seja, tornase um instrumento de controle do uso da visitação para as UCs e, nesse caso, uma medida para a diminuição dos resíduos gerados pela visitação. O Núcleo de São Sebastião é um importante meio para o desenvolvimento da educação ambiental, contudo, um de seus principais atrativos, a Praia Brava de Boiçucanga, pode estar sofrendo com a geração de lixo ocasionada pela visitação no local.

Deste modo, entende-se como papel da UC a promoção da visitação e o desenvolvimento da educação ambiental. No entanto, questiona-se o porquê do lixo gerado com a visitação e o que a educação ambiental tem feito diante dessa questão, qual a sua importância frente a este problema. A partir disso, a presente pesquisa teve como objetivo identificar as ações de educação ambiental desenvolvidas no Parque Estadual da Serra do Mar - Núcleo de São Sebastião, de modo a buscar minimizar os impactos gerados pela visitação na Praia Brava de Boiçucanga, especificamente aqueles vinculados a geração de resíduos.

\section{METODOLOGIA}

A pesquisa de abordagem qualitativa (MARCONI, LAKATOS, 2008), se desenvolveu por meio de etapas, com intuito de alcançar o objetivo proposto. A partir do método dedutivo (MARCONI, LAKATOS, 2009), se considerou as premissas de desenvolvimento da educação ambiental em UCs, especificamente a categoria parques, como sendo uma forma de conscientizar e sensibilizar os visitantes, controlar a visitação e minimizar seus impactos.

A pesquisa teve caráter exploratório e descritivo (MARCONI, LAKATOS, 2008), na tentativa de atender ao objetivo proposto. Na primeira fase, foi realizada a coleta dos dados, por meio de pesquisa bibliográfica e documental (MARCONI, LAKATOS, 2008), para que houvesse maior compreensão dos assuntos relacionados ao objeto de estudo da pesquisa, auxílio no processo de coleta de dados e na elaboração dos instrumentos que nortearam os roteiros de observação e entrevista.

Posteriormente, utilizou-se da técnica de observação sistemática não participante (MARCONI, LAKATOS, 2008), a partir da elaboração de dois roteiros de observação, sendo 
o primeiro referente ao espaço, estrutura e elementos do percurso (placas informativas e interpretativas, panfletos, entre outros) presentes no acesso à trilha interpretativa autoguiada da Praia Brava de Boiçucanga. O segundo, com foco na visitação, foi selecionada uma amostra aleatória de trinta e cinco visitantes, haja vista que a trilha recebe em média dois mil visitantes por ano, conforme informações cedidas pelo Parque, apesar da visita não ser fiscalizada e/ou controlada. Isto posto, ao longo de dez dias (dia 14 ao dia 24 de Abril/2017) e em períodos alternados (manhã e tarde), a pesquisadora atuou como observadora e, por isso, esteve em pontos estratégicos dos locais (trilha e praia), de forma que fosse possível observar o comportamento dos visitantes sem interferir em suas atitudes.

A segunda fase da pesquisa foi realizada mediante entrevista estruturada, a partir de perguntas abertas destinadas ao gestor do Parque, na qual as respostas foram descritas pelo pesquisador no momento da realização. Posteriormente à coleta e descrição dos dados, foi desenvolvida a separação das principais partes (categorias de interesse) para a análise dos dados (MARCONI, LAKATOS, 2008).

\section{RESULTADOS}

A trilha de acesso à Praia Brava de Boiçucanga é uma trilha com dificuldade moderada e se localiza a 35,1 km do centro de São Sebastião, entre as praias de Maresias e Boiçucanga. Seu acesso oficial é na Rodovia Rio-Santos Km 160, no qual o visitante segue pela estrada da Praia Brava até o portal de entrada do Parque Estadual da Serra do Mar. Desde a estrada da Praia Brava, a trilha tem um total de 3,2 km de extensão, sendo aproximadamente 1h e 30min de caminhada até a Praia Brava. O portal de entrada do Parque, que dá acesso à trilha, está localizado nos primeiros $500 \mathrm{~m}$ de extensão (FUNDAÇÃO FLORESTAL, [?b]).

A largura da trilha é irregular durante todo o percurso e caracteriza-se por uma área essencialmente natural, com pouca presença de ações de manejo na trilha. Seu formato é linear, pois se inicia no portal de entrada do Parque e termina no acesso à Praia Brava, sendo o retorno pela mesma rota, o que aumenta as chances dos visitantes se encontrarem ao longo do percurso (LECHNER, 2006). No entanto, a trilha não permite acessibilidade à pessoas com deficiência física, devido a sua declividade e irregularidade do solo, sendo que em determinados momentos a passagem torna-se bem estreita.

Na estrada da Praia Brava não há nenhuma sinalização informando para onde o visitante deve ir para encontrar a entrada do Parque e início da trilha. Consta apenas sinalização referente ao estacionamento chamado Da Brava, localizado próximo ao portal de entrada. Essa parte do percurso é precária, íngreme e formada por pisos de pedra em formato de hexágonos, sendo que na rua existem diversas residências que podem ser consideradas irregulares, pois estão em área pertencente ao Parque, conforme mostra o zoneamento do Parque sobre as áreas de recuperação, que sofreram alterações antrópicas e as quais busca-se a reconstituição do local degradado (BRASIL, 2000).

Nessa estrada constatou-se a presença de diversos tipos de lixo, como sacolas plásticas e embalagens originárias das residências. Não foi possível confirmar se o lixo foi deixado pelos visitantes. Em determinado momento da observação, em contato com os vigilantes do 
Parque, foi relatado que anteriormente havia um latão de lixo próximo ao portal de entrada utilizado pelos visitantes e moradores locais, entretanto, por motivos desconhecidos, até o momento da realização da coleta de dados, esse latão já não havia mais.

Após o portal de entrada, a trilha tem maior aclividade, e caracteriza-se por ter solo arenoso, aspecto mais rústico, presença de muitos galhos sem nenhuma manutenção, raízes expostas susceptíveis a erosões resultantes de períodos de chuva (LECHNER, 2006) e com diversas pedras e buracos no percurso, sendo necessário que os visitantes tomem cuidado ao caminharem.

Em continuidade ao caminho da trilha, há o calçamento com paralelepípedos do percurso, além de canaletas (cimentadas) e degraus (pedra e barro). Ressalta-se que em períodos de chuva, estes elementos apresentam riscos aos visitantes, devido a trilha ser íngreme e por conta de sua superfície lisa, o que a torna escorregadia. Ao longo do percurso, pelo menos até o presente momento, não havia sido detectada a presença de lixeiras.

A partir do portal de entrada do Parque, são encontrados alguns tipos de lixo com pouca frequência, como sacolas plásticas e pedaços de plástico, embalagens de cigarro e partes de outros objetos que não puderam ser identificados. Não é possível saber se foram deixados por visitantes enquanto passavam pela trilha, já que no momento da coleta de dados os resíduos já estavam no local.

A trilha possui três placas informativas e três placas interpretativas, que estão dispostas desde o início da estrada da Praia Brava até 700 metros após o portal de entrada do Parque, pois em seguida o percurso já não contém mais placas. Conforme pontuado por Vasconcellos (2006). As trilhas autoguiadas necessitam manter as características de abordagem de uma/ou para uma atividade interpretativa: amena, pertinente, organizada e temática, bem como seguir a uma estrutura lógica, com começo, meio e fim, com forma resumida e que seja atrativa ao visitante. Isso é o que irá distinguir uma trilha autoguiada interpretativa de uma caminhada que contém somente uma série de informações distintas.

As placas foram observadas na ordem em que estão no percurso.

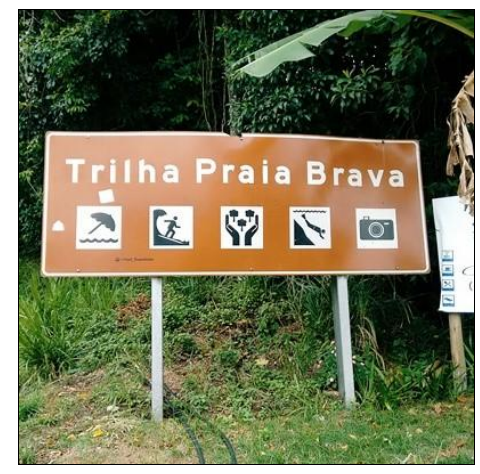

Figura 01: Primeira placa Fonte: A autora (2017)

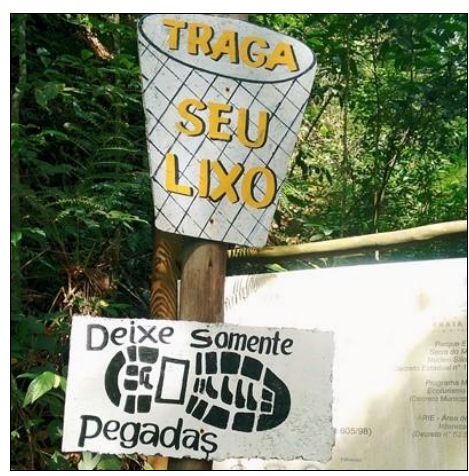

Figura 02: Segunda placa Fonte: A autora (2017)

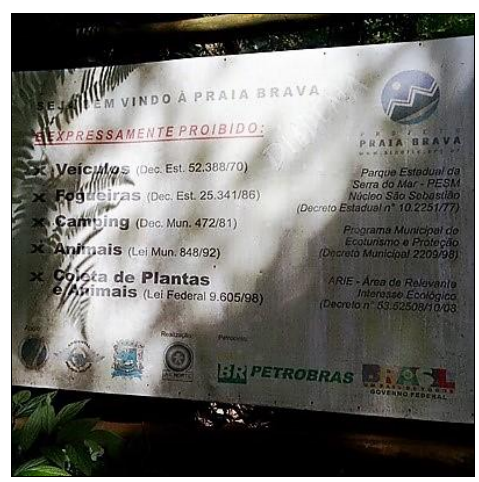

Figura 03: Terceira placa Fonte: A autora (2017) 


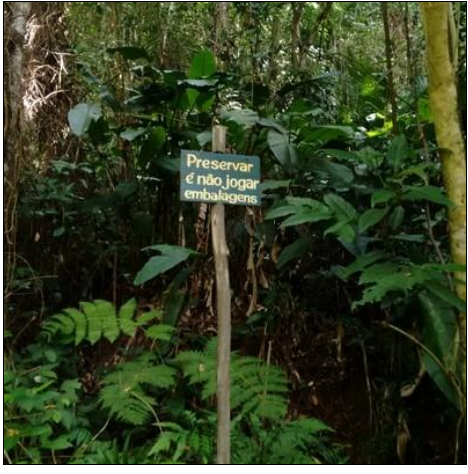

Figura 04: Quarta placa Fonte: A autora (2017)

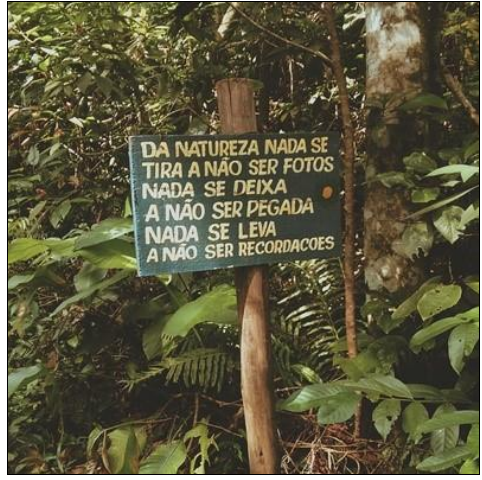

Figura 05: Quinta placa Fonte: A autora (2017)

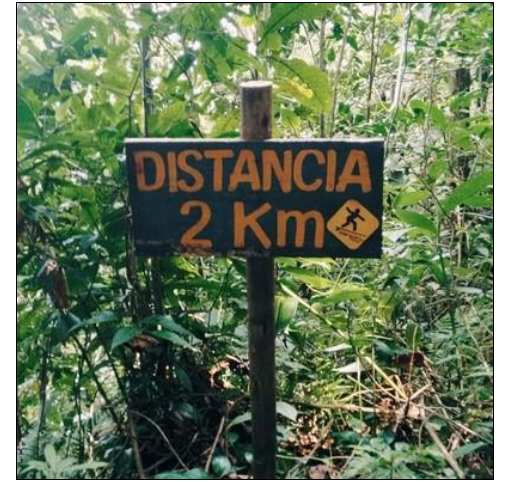

Figura 06: Sexta placa Fonte: A autora (2017)

A primeira placa (Figura 01) é informativa, localiza-se ao lado da rodovia Rio-Santos Km 160, e traz informações de localização da trilha da Praia Brava, contendo cinco símbolos referentes às atividades que podem ser realizadas no local (aproveitar a praia, prática do surf, patrimônio natural, mergulho e mirante).

A segunda placa está fixada no portal de entrada do Parque e contém informações transmitidas de maneira simples para sensibilização dos visitantes, sua temática tem o intuito de informar e conscientizar a respeito do lixo, como mostra a figura 02. Conforme as ideias de Ham (1992) sobre os elementos necessários para que uma parada temática seja positiva, verifica-se que essa placa tem características condizentes ao proposto, com foco para o tema da importância do visitante trazer de volta o lixo da trilha, com frase sucinta e com a imagem que desperta o interesse de quem pára no portal de entrada do Parque.

A terceira placa (Figura 03) localiza-se no portal do Parque e contém informações sobre as leis que norteiam as práticas proibidas no local. A placa é a que contém maior detalhamento em termos de informações, com título, início, meio e fim, e se tratar de uma placa com mais informações a respeito das leis e instituições que contribuem para proteção do local.

A quarta placa (Figura 04) localiza-se próximo ao início da trilha, contém informações com o objetivo de sensibilização e interpretação ambiental do visitante sobre a poluição em geral. A placa tem foco e título-tema voltados para a importância da preservação, chama a atenção do visitante para o seu significado e é complementada pelas ideias da quinta placa interpretativa, que se utiliza de linguagem simples e de fácil entendimento a todos os tipos de público em relação à degradação e retirada de elementos naturais do lugar.

A quinta placa, localiza-se próximo ao portal de entrada do Parque e traz informações que tem por intuito sensibilizar o visitante sobre coleta de fauna e flora e sobre poluição em geral, presente na figura 05. Do ponto de vista da interpretação ambiental, com esta placa pretende-se, não chamar apenas a atenção para os resíduos deixados no local, mas também a importância de não retirar elementos naturais do atrativo.

A sexta e última placa (Figura 06), dispõe de dados a respeito da distância restante para terminar a trilha e se localiza a 700 metros do portal de entrada do Parque, sendo esta a 
única placa com esse tipo de informação. A partir das ideias de Vasconcellos (2006) a respeito do que uma trilha autoguiada deve conter, considera-se necessário haver uma placa introdutória, com o objetivo de chamar a atenção do visitante para as características e informações pertinentes à trilha, como extensão, grau de dificuldade e tempo de percurso, assim como o intuito de informar em relação ao tema interpretativo, despertando no visitante o desejo de percorrê-la.

Partindo do que apontam os autores Ham (1992) e Vasconcellos (2006) sobre as características necessárias a uma parada interpretativa, somente a segunda, quarta e quinta placas presentes na trilha possuem características de informar e educar o visitante sobre a importância de respeitar e preservar o local. Assim considera-se que seja necessário haver um número maior de paradas (com placas definitivamente interpretativas) para que a sensibilização e abordagem aconteçam de maneira lógica e mais efetiva diante da proposta da interpretação ambiental.

Com relação aos panfletos, estes são distribuídos aos visitantes apenas durante as visitas/passagens pela sede do Núcleo, e em atrativos e/ou palestras realizadas pelos monitores em escolas da região, por exemplo.

O panfleto deste Núcleo do Parque possui inicialmente os logotipos dos núcleos do Parque e informações sobre a Mata Atlântica. Posteriormente, são encontradas informações para que o visitante conheça o Núcleo de São Sebastião e seus atrativos, e também a pressão que o crescimento urbano gera sobre as áreas protegidas e importância de sua equipe de fiscalização contra invasões e infrações no local. Por fim, são pontuados os cuidados e as precauções que o visitante deve ter durante a visita aos atrativos e o que deve ser feito para não degradar o local. Dentre as informações presentes no panfleto, um de seus principais objetivos é transmitir conhecimentos aos visitantes a respeito da importância da Mata Atlântica e do Parque, de forma que estes compreendam a relevância de se conservar esses espaços. Assim, este panfleto seria considerado um dos instrumentos de interpretação ambiental que o Parque se utiliza para chamar atenção dos visitantes.

O panfleto específico do atrativo Praia Brava, contém diversas imagens do atrativo, com informações sobre a distância da praia ao centro de São Sebastião, sua localização, as características que o visitante irá encontrar durante a visita, o grau de dificuldade da trilha e suas características. Em seguida, há informações a respeito da importância de conservação da Mata Atlântica. São informados ainda, seguidos de um mapa da trilha, a distância e duração da caminhada na trilha para chegar a Praia Brava, com dicas do que deve ser feito para evitar degradação do atrativo e quais pertences levar (FUNDAÇÃO FLORESTAL, [?b]).

De acordo com as informações presentes, este panfleto é utilizado também como uma forma de conscientização do visitante, ou seja, é um dos instrumentos de interpretação ambiental para alertar os visitantes sobre o que deve ser feito ou não durante a visita a Praia Brava e, especificamente, sobre a necessidade de se trazer o lixo gerado de volta e a importância de se preservar a fauna e flora que vivem no local.

Já em relação à observação do comportamento dos visitantes na trilha, foram escolhidos de forma estratégica, sem interferir nas atitudes dos visitantes, três pontos (I, II e 
III), a partir do portal do Parque. Ao todo, foram observados trinta e cinco visitantes nestes três pontos.

No ponto I, foi possível observar os visitantes que prestavam ou não atenção às informações contidas na quinta placa, sendo que nos outros pontos de observação não haviam placas. Ao todo, foram observados treze visitantes nesse ponto, sendo que cinco retornavam da praia e oito iam para a praia. Notou-se que a maioria das pessoas que passaram pelo local no momento já conhecia a trilha ou observavam superficialmente a placa.

Observou-se ainda que apenas dois dos visitantes pararam para observar a placa, tirar fotos e caminharam devagar pela trilha, demonstrando com isso que a placa interpretativa possa ter passado despercebida pelos outros visitantes enquanto conversavam/andavam apressados ou que os mesmos apenas observaram rapidamente enquanto passavam pelo local. Visto que, como citado anteriormente, a trilha possui placas informativas e interpretativas até 700 metros após o portal de entrada do Parque, pois os $2 \mathrm{~km}$ restantes não possuem placas, e, desta forma, o visitante não possui oportunidade de interpretar outras placas e/ou outras informações durante o restante do caminho.

Dentre as situações observadas, houveram visitantes que passaram pela trilha com dificuldade em função de um deslizamento que ocorreu, fazendo com que os mesmos criassem um caminho alternativo por cima do deslizamento. Observou-se também, que dois dos visitantes degradaram elementos naturais pelo fato destes se utilizarem das plantas presentes no local como um suporte de segurança ao passarem com dificuldade pela trilha.

Dos visitantes observados, somente um jogou lixo na trilha e, portanto, pensa-se que o visitante passou despercebido pela placa interpretativa ou o mesmo não estava sensibilizado em relação a importância de preservar o espaço. A ausência de lixeiras próximas ao portal de entrada, também pode ser um dos motivos que levaram esse visitante a descartar o lixo no chão, caso contrário, poderia ter descartado a embalagem diretamente na lixeira.

No ponto II, foram observados quatorze visitantes, no qual cinco retornavam da praia e nove iam para a praia. Por não haver placas nesse ponto, a observação ficou restrita ao comportamento dos mesmos e, nesse caso, cinco visitantes passaram juntos pela trilha conversando e dois deles do sexo feminino retiraram plantas e pedras próximas à guarita e levaram consigo, possivelmente estes entendem como uma forma de levar algo como recordação do lugar que visitaram ou não prestaram atenção às placas interpretativas e informativas que alertavam a respeito da remoção de elementos naturais do espaço. Um dos visitantes trazia consigo um galho que servia como apoio para o trajeto e que talvez poderia ser usado por todos para percorrer a trilha em lugares em que o percurso é mais difícil, com buracos e partes íngremes.

Todos os visitantes observados nesse ponto fizeram barulho ao passarem conversando/falando alto, provavelmente por que todos passaram pela trilha acompanhados ou em grupo e, de acordo com o que pode ser observado com relação aos visitantes que fazem o percurso acompanhados, em diversos momentos conversam sobre as dificuldades da passagem pela trilha, assuntos pessoais, detalhes na paisagem que lhes chamam a atenção, como as árvores, flores ou algum animal que tiveram a chance de observar, entre outros. 
Dois dos visitantes pararam com a finalidade de descansar e aproveitaram para tirar fotos da guarita e contemplar a paisagem da serra. O ponto II, por se localizar na metade da trilha e possibilitar a observação da paisagem é um lugar de parada, no entanto, não tem placas interpretativas que, conforme aponta Vasconcellos (2006), poderiam deixar a parada mais interessante e explicativa, havendo detalhes e informações a respeito do lugar visitado.

No ponto III, foram observados oito visitantes, no qual seis iam para a praia e dois retornavam da praia. Nesse ponto também não haviam placas, o que restringiu a observação, novamente ao comportamento dos visitantes, dos quais, um casal que passou pela trilha falando alto e parou para tirar fotos no mirante, foi possível observar que os mesmos entraram na trilha no período da manhã (por volta das 09 horas) e voltavam da praia à tarde (por volta das 13 horas). $\mathrm{O}$ homem consumia uma lata de cerveja ao entrar na trilha pela manhã e à tarde não dava para saber se retornou ou não com a lata de cerveja, desta forma, não é possível afirmar se o mesmo trouxe o lixo consigo na mochila ou o deixou na praia.

Outra situação observada, foi relativa a uma família com quatro pessoas, duas do sexo masculino (um mais velho e o outro adolescente) e duas do sexo feminino (uma mulher mais velha e uma adolescente) se ajudavam a passar pela trilha em lugares mais difíceis e falavam alto sobre os cuidados para não caírem. Aparentemente já conheciam o percurso e levavam consigo varas de pescar, deste modo, pensa-se que estavam indo para praia com o intuito de realizar a atividade de pesca, atividade considerada ilegal perante a Lei 9.605/98 que dispõe das proibições de atividades em UCs, conforme informava a terceira placa disposta na trilha.

Já na Praia Brava foram observados trinta visitantes e, durante a observação, um casal que chegou na praia bebendo cerveja deixando as latas próximo a mata ao saírem para caminhar pela praia e também após saírem da praia, mantendo-as no mesmo local. Foi constatado ainda que no local já havia acúmulo de lixo, como, por exemplo, garrafas PET, fraldas descartáveis, partes de roupas, sacolas plásticas com outros tipos de lixo amarrados a um arbusto, entre outros objetos, provavelmente deixados por visitantes anteriores que se utilizaram da sombra das demais árvores próximas no período em que permaneceram na praia (figuras 07, 08 e 09).

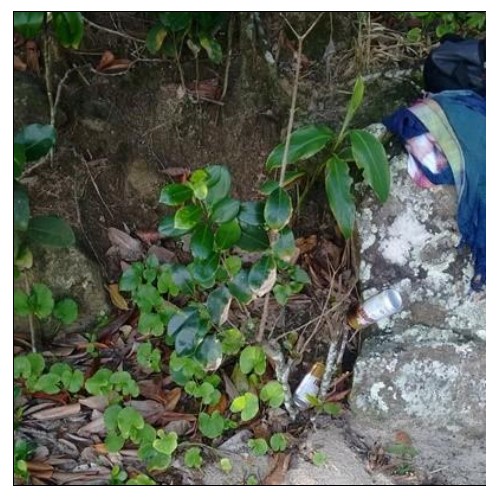

Figura 07: Latas de cerveja Fonte: A autora (2017)

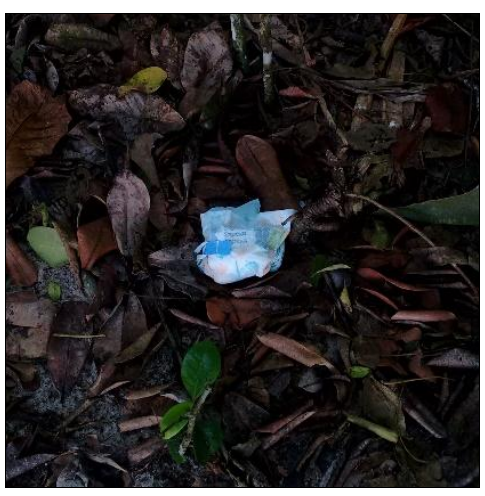

Figura 08: Fralda descartável Fonte: A autora (2017)

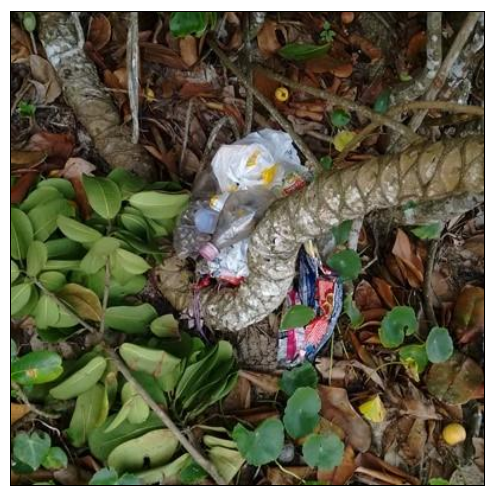

Figura 09: Lixo amarrado Fonte: A autora (2017) 
Dois dos visitantes observados chegaram ao local e realizaram uma fogueira, conforme mostra a figura 10, que de acordo com o decreto Estadual 25.341/86, é considerada uma prática ilegal na área (informação também contida na terceira placa). Pensa-se que se tratavam de pessoas que moram no município e que tinham ciência de que a atividade é algo ilegal, pois traziam consigo poucos utensílios e mantinham cautela enquanto faziam a fogueira. Os visitantes apagaram a fogueira assim que saíram do local e deixaram os resíduos desta na areia.

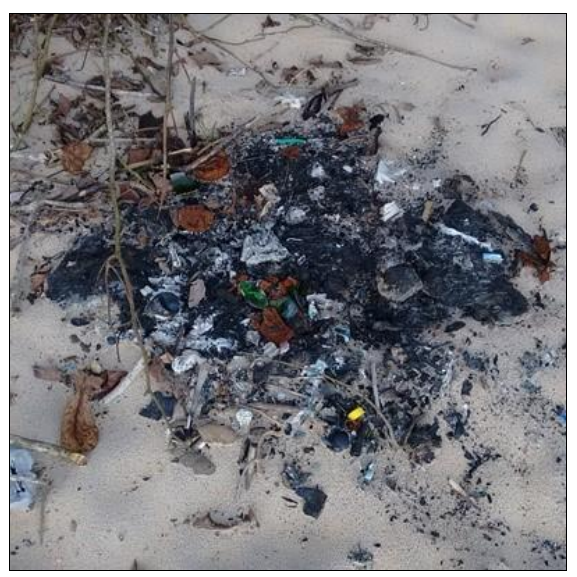

Figura 10: Resíduos provenientes da fogueira Fonte: A autora (2017)

Observou-se ainda que doze dos visitantes recolheram seus lixos, pois fumavam e comiam no local e, além disso, portavam sacolas plásticas ou outros meios para guardar o lixo no momento em que estiveram na praia. E, além disso, observou-se um casal que estava com seu animal de estimação (cão) e, portanto, realizou uma prática considerada ilegal devido a normatização da visitação no local, de acordo com a Lei Municipal 848/92 (informação também contida na terceira placa).

Em sua maioria, os visitantes observados apresentaram comportamentos semelhantes e considerado práticas habituais de uso de praias, como tomar sol, praticar surf, passar protetor solar, tirar fotos. Nenhum dos visitantes observados retirou elementos naturais do local. Em geral, foram encontrados diversos tipos de lixo na areia, próximos às pedras e ao mar, como garrafas PET, partes de pranchas de surf, embalagem de cigarro, pente, entre outros objetos.

Pode-se ponderar que a maior parte do lixo presente na praia seja proveniente do mar, trazido pela correnteza de outras praias ou outros lugares. No entanto, existem visitantes que ao permanecerem no local chegaram a deixar o lixo na areia ou próximo a mata, supostamente por motivos de falta de consciência e/ou falta de percepção em relação aos danos que esses resíduos causam ao serem deixados no ambiente e a estarem em contato com a fauna e flora locais, ou mesmo tiveram essa atitude pela ausência de lixeiras na área que supostamente poderia interferir no comportamento do visitante na praia.

Durante a entrevista, a primeira pergunta designada ao gestor do Parque Estadual da Serra do Mar - Núcleo de São Sebastião, foi em relação a como ocorre a visitação (acompanhamento e fiscalização) no Parque. Segundo o gestor, “[...] a visitação no Parque 
Estadual da Serra do Mar - Núcleo de São Sebastião ocorre informalmente, já que não há estruturação dos atrativos para que se tenha controle sobre a visitação [...]”. Deste modo, é possível afirmar que o controle dos impactos da visitação na UC precisa de planejamento e acompanhamento adequado para ocorrer de forma eficaz e isso só é possível se houver estrutura adequada nos atrativos para oferecer suporte aos visitantes e aos responsáveis pela fiscalização do local. No entanto, a visitação no Núcleo ocorre de maneira informal, sem maior planejamento, acompanhamento e estruturação adequada, o que dificulta ou até impossibilita a fiscalização sobre os impactos gerados pelos visitantes.

Dando continuidade à resposta referente ao acompanhamento e fiscalização dos visitantes, o gestor pondera que "[...] é realizado um apoio de vigilantes nos finais de semana e feriados, de forma bem pontual, onde aproveita-se para fiscalizar os usos pelos turistas e realizar levantamento de demandas de segurança ou qualquer tipo de manutenção”. Assim, compreende-se que isso ocorre como um meio em que a gestão do Núcleo se utiliza para suprir a falta de estruturação nos atrativos e, ainda que de forma pontual, fiscalizar a visitação e os problemas com os impactos gerados, bem como verificar as necessidades de segurança e manutenção. No entanto, de acordo com as observações, a falta de manutenção nos atrativos pode ser um dos agravantes para que os impactos ocorram.

As atividades de educação ambiental desenvolvidas no (e pelo) parque são questionadas, tomando por base os objetivos centrais das UCs, que é favorecer condições e desenvolver a educação ambiental e interpretação ambiental, para proporcionar vivências e experiências aos visitantes diretamente com o meio natural por meio da sensibilização (BRASIL, 2000; PÁDUA, 2012). Assim, de acordo com o gestor, os projetos voltados à educação ambiental realizados pelo Núcleo são "[...] o Projeto Escola no Parque, onde realizamos palestras temáticas em todos os sétimos anos das escolas municipais e algumas particulares (diferentes anos); Também realizamos palestras para jovens de projetos sociais e outras Instituições (até de fora de São Sebastião), conforme demanda e disponibilidade da gestão [...]". Desse modo, considera-se que a realização de palestras temáticas é uma das estratégias de educação e interpretação ambiental utilizadas pelo Núcleo para interagir com as escolas e sensibilizá-los sobre a relevância de proteger o Parque e seus recursos naturais, que tem ligação direta com a qualidade de vida da comunidade que vive em seu entorno.

Partindo desse ponto, conforme aponta Delgado (2000), cabe salientar que as palestras consistem em uma das técnicas que mais solicitam melhor elaboração, instrumentos audiovisuais e conhecimentos ligados à condução e estímulo a interação dos indivíduos. Todavia, em nenhum momento é abordado sobre a interpretação com os visitantes, visto que a realização de palestras pelo Núcleo é direcionada apenas às escolas e não aos visitantes, em geral, que consistem em seu maior público. Desse modo, não é possível afirmar que exista uma forma interpretativa eficaz para mudar o comportamento do visitante para os impactos ambientais gerados pela visitação, especificamente a geração de resíduos. Seria preciso mais do que o trabalho desenvolvido com as escolas da região, ou seja, pondera-se que a interpretação ambiental, tida enquanto educação ambiental, ao visitante é realizada apenas por meio do uso das placas interpretativas disponibilizadas na trilha e na distribuição de panfletos. 
Retomando a ideia tratada anteriormente a respeito das estratégias utilizadas, são apontadas a realização de "[...] atividades de campo com as mesmas escolas/projetos, realizada na trilha do Ribeirão de Itú e outras também na trilha da Praia Brava [...]", assim, durante essas atividades, conforme Pádua (2012) esclarece, é possível compartilhar conhecimentos e curiosidades relacionadas à biodiversidade ou espécies que só existem na região e as complexidades que envolvem os assuntos socioambientais, conservação e a sociedade como parte desse processo. No entanto, trata-se ainda de educação ambiental desenvolvida com grupos escolares e não com os visitantes, em geral.

Dentre os temas abordados durante a realização das atividades de educação ambiental com as escolas apontadas pelo gestor estão a "[...] Mata Atlântica, Unidade de Conservação, Parque Estadual, Biodiversidade, Resíduos Sólidos e outros", com a finalidade "[...] de levar conhecimento aos jovens/adultos e trazê-los para discussão sobre conservação e preservação das florestas, apontando a realidade local". Isso reafirma o pressuposto de Pádua (2012), quando comenta sobre a importância de abordar esses temas nos programas educativos, estimulando cada vez mais a interação da comunidade com a UC, por meio de assuntos que valorizem os espaços naturais e modifiquem a ideia de suas proibições.

Em geral, o Núcleo, ao abordar assuntos voltados para importância de se preservar os atrativos, bem como sua fauna e flora em projetos e escolas da região, transmitem as crianças desde muito cedo sobre a importância de não jogarem/deixarem seu lixo no chão e a necessidade de preservar os espaços naturais. Sendo assim, quando discutido sobre como e por quem são planejadas e executadas as atividades de educação ambiental durante a visitação à UC, o gestor afirma que "[...] todo planejamento e execução são realizados pela gestão do núcleo de São Sebastião, tanto pelo gestor, monitores e vigilantes". Contudo, salienta-se que essas atividades são realizadas para as escolas e não para a visitação como um todo, exceto quando solicitado acompanhamento a grupos de visitantes.

Ademais, os monitores do Núcleo " [...] prestam serviços por empresas terceirizadas e trabalham no atendimento ao uso público (EA) e nas atividades relacionadas à Gestão do Núcleo de São Sebastião (pesquisa, proteção, interação socioambiental e outros). Há capacitação interna para que possam realizar as atividades junto aos visitantes, mas apenas sobre demanda. Não há acompanhamento de visitação diária por conta da logística complicada entre a sede administrativa e os atrativos oficiais (trilhas do Ribeirão do Itu e Praia Brava), que estão distantes 18 quilômetros. Quando em atividades de educação, tratam dos temas apontados anteriormente". De acordo com este enunciado, pode-se entender que o número de monitores que o Núcleo dispõe não é suficiente para atender à demanda dos principais atrativos, incluindo nestes a Praia Brava, visto que o número de visitantes é muito superior, principalmente em finais de semana e feriados, e a distância entre os principais atrativos (trilhas e praia) da sede é algo que de fato, dificulta muito e/ou impossibilita seu acompanhamento diário.

Visto que a educação ambiental desenvolvida em UCs é calcada em diretrizes que dão base para o seu desenvolvimento, por meio do Plano de Manejo, que dispõe dos programas de manejo, diagnóstico, zoneamento e no papel do Conselho Gestor, que contribui para 
manutenção e proteção da diversidade local (BRASIL, 2000), foram questionadas as diretrizes que dão base para a realização das atividades de educação ambiental no Parque. No entanto, o que se obteve como resposta não poderiam ser consideradas diretrizes, pois são abordados os temas direcionados " [...] a aproximação com a sociedade, ofertando conhecimentos gerais e específicos relacionados a conservação e proteção do meio ambiente, e relacionados também aos ecossistemas, fauna e flora local".

Desse modo, é possível compreender que a Política Nacional de Educação Ambiental (BRASIL, 1999), em momento algum foi mencionada e esta traz em seus princípios básicos, que a educação ambiental deve englobar a participação da sociedade, por meio de uma abordagem humanista e participativa, bem como dar enfoque nas questões ambientais locais, regionais, nacionais e globais, o que não foi possível de se observar.

Adentrou-se então, na questão da geração de resíduos pelos visitantes do Parque e sobre a forma como os visitantes são informados sobre a geração de lixo e descarte no ambiente natural, na qual se destacou que são "[...] através, principalmente, dos apontamentos relacionados à quantidade de lixo nas praias e no mar, que em sua maioria são provenientes dos moradores que descartam lixo nos rios e em locais indevidos", para tanto, observou-se que alguns dos visitantes continuam a deixar seus lixos.

Quando indagado sobre o tipo de lixo que os visitantes costumam deixar no Parque, o gestor esclarece que "[...] são plásticos, que proveem de embalagens de salgadinhos, biscoitos e outros do tipo, como garrafas plásticas de refrigerantes/sucos e latas de alumínio (cervejas/refrigerantes)". Assim, e com base nas observações, é possível afirmar que em sua maioria os visitantes deixam esses tipos de lixo no Parque, por vezes em que já chegam no atrativo comendo ou bebendo, ignoram as placas informativas e interpretativas e descartam seu lixo na trilha ou deixam na praia quando levam alimentos e bebidas para o período em que vão permanecer no local.

Logo, a partir do pontuado por Pires (2010), a disposição inadequada dos resíduos produzidos pela visitação compromete rios, mares, lagos e estuários, as margens de estradas, caminhos e trilhas e, consequentemente a paisagem, que vem a ser um dos ambientes mais atingidos pela disposição inadequada do lixo. Desse modo, em relação aos locais para descarte do lixo pelo visitante, foi informado pelo gestor que "[...] Não há locais para descarte correto dos resíduos nos atrativos, é solicitado que tragam de volta e destinado nas lixeiras dos estacionamentos ou qualquer outro local fora do PESM", sendo que esta informação está contida na segunda placa interpretativa da trilha, com o intuito de conscientizar os visitantes sobre o lixo gerado e a necessidade de trazê-lo de volta durante sua visita.

Nesse sentido, e em continuidade, para conter a disposição inadequada do lixo produzido pelo visitante "[...] solicitamos que tragam de volta os resíduos e descartem em locais corretos. Já os resíduos deixados por estes, são recolhidos em atividades organizadas pela Gestão (semanal ou quinzenal)”. Além disso, o lixo gerado pelo visitante, "[...] são acondicionados em sacos plásticos e encaminhados para lixeiras nos bairros”. Conforme foi possível de se observar entre as placas interpretativas dispostas na trilha, especificamente a 
segunda placa, há informações sobre o descarte e para que o visitante traga o lixo de volta do atrativo. Além disso, os visitantes são informados e alertados sobre a necessidade de se preservar o local que estão visitando.

Já em relação as implicações que o lixo gerado e deixado tem para a atividade turística, é apontado que, "[...] não há implicações diretas na quantidade de visitação, pois a quantidade de resíduos gerado pelos visitantes é baixa e geralmente agrupado. No caso da Praia Brava, a maior quantidade de resíduos é trazida pelo mar com as ressacas do oceano que remexem o fundo e suspendem estes resíduos". Contudo, a partir das observações realizadas, verificou-se que a praia contém diversos tipos de lixo provenientes do mar, como garrafas PET que podem ser encontradas em pedras e na areia, mas também notou-se que há lixos provenientes dos próprios visitantes que vão até o local e ao saírem não o recolhem, agrupam o lixo nas árvores, terminam de fumar, beber ou comer e deixam o lixo no lugar em que estavam, e os que desenvolvem práticas ilegais como fogueiras e deixam seus resíduos na areia.

\section{CONCLUSÕES}

De acordo com os resultados, entende-se que a maior parte do lixo presente na praia é proveniente do mar, trazido pela correnteza de outras praias ou outros lugares, no entanto, existem visitantes que ao permanecerem no local deixaram o lixo na areia ou próximo a mata, por motivos de falta de percepção em relação aos danos que esses resíduos causam no ambiente e à fauna e flora locais, ou pela ausência de lixeiras na área que supostamente poderiam interferir no comportamento do visitante na praia.

Diante disso, conclui-se que o principal foco da educação ambiental quando trabalhada com os visitantes em UCs é de sensibilizar e conscientizar os mesmos para o uso racional das áreas naturais. E para que isso ocorra de maneira eficaz, é necessário que se utilize, principalmente, dos instrumentos interpretativos como um número adequado de placas informativas e interpretativas. Elas orientam o visitante a respeito das características e da importância do local que está sendo visitado, bem como a presença de lixeiras e condições de estrutura adequadas para a visitação e para que os impactos sejam evitados, o que não acontece no caso específico da Praia Brava.

Para a visitação, o Parque também se utiliza dos panfletos que, apesar das informações contidas, são distribuídos somente em determinadas ocasiões, seja quando os visitantes passam pela sede do Núcleo ou pontualmente nos atrativos, o que dificulta o acesso para a maioria deles, já que estes se dirigem diretamente à trilha. Durante as observações relativas ao comportamento dos visitantes na trilha e na Praia Brava, apesar de ser considerado um número pequeno, muitos geraram lixo. Ponderou-se na entrevista realizada com o gestor sobre a educação ambiental para os visitantes desenvolvida pelo Parque, que esta é realizada de maneira informal, não trata das placas, possui fiscalização apenas em determinados momentos e as atividades (palestras e atividades de campo) são mais direcionadas às escolas da região e não diretamente aos visitantes, em geral. Neste contexto, não há garantia de que a 
interpretação ambiental seja efetiva, nem consiga controlar a visitação e ao mesmo tempo a não geração de resíduos pelos visitantes que frequentam a trilha e a praia.

\section{BIBLIOGRAFIA}

BARROS, Silvio M. Turismo e unidades de conservação no Brasil. In: Congresso Brasileiro de Unidades de Conservação, 1, 1997, Curitiba. Anais. Curitiba: Iap: Unilivre, 1997. v. 2, p. $298-303$.

BRASIL. Lei Federal n. 9.985, de 18 de julho de 2000. Regulamenta o art. 225, § 1o, incisos I, II, III e VII da Constituição Federal, institui o Sistema Nacional de Unidades de Conservação da Natureza e dá outras providências. Brasília, DF.

BRASIL. Lei $n^{\circ}$ 9.795, de 27 de abril de 1999. Institui a Política Nacional de Educação Ambiental. Ministério do Meio Ambiente, Brasília, 1999.

DELGADO, Jesus. A interpretação ambiental como instrumento para o ecoturismo. In: SERRANO, Célia (Org.). A educação pelas pedras: ecoturismo e educação ambiental. São Paulo: Chronos, 2000. p. 155-169.

FUndaÇÃo Florestal. Parque Estadual da Serra do Mar - Núcleo de São Sebastião. Imprensa oficial, [?a].

FUNDAÇÃO FLORESTAL. Praia Brava. Imprensa oficial [?b].

GIRALDELLA, Heloana; NEIMAN, Zysman. Planejamento e gestão em áreas naturais protegidas. In: NEIMAN, Zysman; RABINOVICI, Andréa (Org.). Turismo e meio ambiente no Brasil. Barueri: Manole, 2010. p. 124-148.

GUIMARÃES, Mauro. A dimensão ambiental na educação. 11. ed. Campinas: Papirus, 2013.

HAM, Sam H. Interpretacion ambiental: una guia práctica para gente com grandes ideas y presupuestos pequeños. North American Press, 1992.

HENRIQUES, Jayme Henrique Pacheco. Ecoturismo, corredores ecológicos e unidades de conservação: O estudo de caso do projeto corredores ecológicos no Espírito Santo. In: COSTA, Nadja Maria Castilho da; NEIMAN, Zysman; COSTA, Vivian Castilho da. Pelas trilhas do ecoturismo. São Carlos: Rima, 2008. p. 233-245.

LECHNER, Larry. Planejamento, implantação e manejo de trilhas em unidades de conservação. Cadernos de conservação. Curitiba: Fundação $O$ Boticário de Proteção à Natureza. v. 3, n. 3, p. 01-125, jun. 2006.

MARCONI, Marina de Andrade; LAKATOS, Eva Maria. Fundamentos da metodologia cientifica. 6 ed. São Paulo: Editora Atlas, 2009.

MARCONI, Marina de Andrade; LAKATOS, Eva Maria. Técnicas de pesquisa. 7 ed. São Paulo: Editora Atlas, 2008. 
NEIMAN, Zysman. Ecoturismo e educação ambiental em unidades de conservação: a importância da experiência dirigida. In: COSTA, Nadja Maria Castilho da; NEIMAN, Zysman; COSTA, Vivian Castilho da (Org.). Pelas trilhas do ecoturismo. 2. ed. São Carlos: Rima, 2008. p. 33-49.

PÁDUA, Suzana Machado. Educação ambiental em unidades de conservação. In: MARIA OLATZ CASES (Brasília); WWF-Brasil/IPÊ-Instituto de Pesquisas Ecológicas (Org.). Gestão de unidades de conservação: compartilhando uma experiência de capacitação. Brasília: Áttema Editorial, 2012. p. 201-210.

PHILIPPI JUNIOR, Arlindo; MAGLIO, Ivan Carlos. Política e gestão ambiental: conceitos e instrumentos. In: PHILIPPI JUNIOR, Arlindo; PELICIONI, Maria Cecília Focesi. Educação ambiental e sustentabilidade. Barueri: Manole, 2005. p. 217-256.

PIRES, Paulo do Santos (Ed.). Turismo e meio ambiente: relação de interdependência. In: PHILIPPI JUNIOR, Arlindo; RUSCHMANN, Doris Van de Meene (Org.). Gestão ambiental e sustentabilidade no turismo. Barueri: Manole, 2010, p. 03-29.

SECRETARIA DO MEIO AMBIENTE (SMA). Plano de Manejo do Parque Estadual da Serra do Mar. Secretaria do Meio Ambiente. Instituto Florestal, Divisão de Reservas e Parques Estaduais. São Paulo, SMA, 2006.

VASCONCELLOS, Jane Maria de O. Educação e interpretação ambiental em unidades de conservação. Cadernos de Conservação, v. 3, n. 4. Curitiba: Fundação Boticário de Proteção à Natureza. v. 3, n. 4, p. 01-86, dez. 2006. 